\title{
Short communication: The effects of regrouping in relation to fresh feed delivery in lactating Holstein cows
}

\author{
Anne-Marieke C. Smid, ${ }^{1,2}$ Daniel M. Weary, ${ }^{1}$ Eddie A. M. Bokkers, ${ }^{2}$ and Marina A. G. von Keyserlingk ${ }^{1 *}$ \\ ${ }^{1}$ Animal Welfare Program, Faculty of Land and Food Systems, University of British Columbia, 2357 Main Mall, Vancouver, BC, V6T 1Z6 Canada \\ ${ }^{2}$ Animal Production Systems Group, Wageningen University \& Research, PO Box 338, $6700 \mathrm{AH}$, Wageningen, the Netherlands
}

\section{ABSTRACT}

This study tested whether separating regrouping from the time of fresh feed delivery mitigated the effects of regrouping on cow behavior and milk production. Cows $(\mathrm{n}=26)$ were individually introduced into a stable group of 11 animals/pen fed twice daily. Animals were randomly assigned to early regrouping (at $0300 \mathrm{~h}$, approximately $10.5 \mathrm{~h}$ after fresh feed delivery and $3.5 \mathrm{~h}$ before the next fresh feed delivery) and late regrouping (between 0630 and $0730 \mathrm{~h}$, coinciding with access to fresh feed). For 3 d, starting immediately after regrouping, video recordings continuously monitored feeding and perching (i.e., standing with the 2 front feet in the lying stall) behavior and displacements at the feed bunk. Data loggers were used to quantify lying time and the number of standing bouts; milk production was automatically recorded at each milking. Daily feeding and lying times and the number of standing bouts per day did not differ between treatments or experimental days. Daily perching time and the number of displacements at the feed bunk did not differ between treatments but decreased with experimental day. Average milk production on d 2 and 3 after regrouping (30.6 \pm $1.5 \mathrm{~kg} / \mathrm{d}$ ) was lower than during the $3 \mathrm{~d}$ before regrouping $(32.3 \pm 1.5 \mathrm{~kg} / \mathrm{d})$, but we observed no effect of treatment on this decline. We conclude that regrouping at a time not associated with fresh feed delivery does not mitigate the negative effects of regrouping.

Key words: welfare, mixing, management, social stress

\section{Short Communication}

Regrouping as a management practice in dairy farming is the introduction of new animals into an established group. Cows are typically regrouped to maintain homogeneous groups in terms of reproductive status, stage of lactation, and dietary requirements (Bøe and

Received December 31, 2018.

Accepted March 21, 2019.

*Corresponding author: nina@mail.ubc.ca
Færevik, 2003). Regrouping is common on dairy farms, with cows often regrouped several times per lactation (Cook and Nordlund, 2004). Regrouping can affect social hierarchy (Hasegawa et al., 1997), and cows use a variety of physical and nonphysical interactions to reestablish social relationships in the new group (Kondo and Hurnik, 1990). The number of agonistic interactions is most frequent on the day of regrouping and then gradually declines, returning to baseline after $3 \mathrm{~d}$ (von Keyserlingk et al., 2008).

Lying times decrease after regrouping (Hasegawa et al., 1997; von Keyserlingk et al., 2008), and effects on lying bouts have also been reported (Hasegawa et al., 1997; von Keyserlingk et al., 2008; Schirmann et al., 2011). Regrouping can also reduce DMI, feeding rate, and rumination time (Schirmann et al., 2011) and change the time of day when cows feed (von Keyserlingk et al., 2008). Galindo et al. (2000) showed that low-ranking cows perched (i.e., standing with the 2 front feet in the lying stall) more than middle- and high-ranking cows, suggesting that these cows perched to avoid higher-ranking conspecifics. Regrouped cows may also wish to avoid their new pen mates, especially at times when competition is expected to be greatest. In addition to behavioral effects, regrouping can reduce milk production (Brakel and Leis, 1976; Hasegawa et al., 1997; von Keyserlingk et al., 2008).

Regrouping is often done just after milking, a time that commonly corresponds to the delivery of fresh feed. Cows are highly motivated to feed after the delivery of fresh feed (DeVries and von Keyserlingk, 2005), and this time is associated with an increased number of agonistic interactions at the feed bunk (Val-Laillet et al., 2008a). In an earlier study, von Keyserlingk et al. (2008) found that cows that were regrouped immediately after morning milking, coinciding with access to fresh feed, had a lower feeding time in the first hour after regrouping compared with the hour before regrouping, probably due to an increased number of agonistic interactions. By separating regrouping from fresh feed delivery, it may be possible to reduce the number of agonistic interactions around feeding and thus the disturbance of 
regrouping. Relatively few animals are typically present at the feed bunk from the late evening until early morning (DeVries and von Keyserlingk, 2005; Huzzey et al., 2006; Lobeck-Luchterhand et al., 2014) because most cows are lying down at this time (DeVries et al., 2005); therefore, this period might be best for regrouping.

The aim of our study was to compare the behavior and milk production of dairy cows regrouped either at the time of fresh feed delivery or at a time not associated with fresh feed delivery. As the effects of regrouping are most pronounced for new animals entering an established group (Schirmann et al., 2011), we focused our observation on the regrouped animal. We hypothesized that animals that were regrouped at a time around fresh feed delivery would engage in more agonistic interactions at the feed bunk, have lower daily lying and feeding times, show a higher number of standing bouts, spend more time perching, and show a larger decline in milk production than animals regrouped at a time not associated with fresh feed delivery.

This experiment was conducted in a freestall barn at the Dairy Education and Research Centre (Agassiz, BC, Canada) of The University of British Columbia (UBC) and took place between May and August 2014. All procedures were approved by the UBC Animal Care Committee.

Thirty-two lactating Holstein cows were enrolled as experimental animals in this study. Animals were selected randomly from the main herd and individually introduced into 1 of 4 resident groups. Although heifers in a study by Raussi et al. (2005) did not habituate to regrouping, other studies have shown that calves or cows with more experience with regrouping adjust better to the disruption than do animals with less experience (see review by Bøe and Færevik, 2003). As multiparous cows have more experience with regrouping than primiparous cows, the effects of regrouping may be more pronounced in the primiparous cows. For this reason we used a combination of primiparous and multiparous cows for this study ( $\mathrm{n}=16$ of each). Regroupings were balanced for parity as well as for DIM, projected 305-d milk production, and body size. Regrouped primiparous cows had an average $( \pm \mathrm{SD})$ DIM of $191( \pm 83)$, projected 305-d milk production of 9,530 $\mathrm{kg}( \pm 1,222 \mathrm{~kg})$, weight of $628 \mathrm{~kg}( \pm 49 \mathrm{~kg})$, height of $146 \mathrm{~cm}( \pm 5 \mathrm{~cm})$, and BCS of 3.25 (range: 2.75-3.50). Regrouped multiparous cows had an average $( \pm \mathrm{SD})$ parity of $3.3( \pm 1.8)$, DIM of $273( \pm 100)$, projected $305-$ d milk production of $11,730 \mathrm{~kg}( \pm 1,422 \mathrm{~kg})$, weight of $763 \mathrm{~kg}( \pm 70 \mathrm{~kg})$, height of $148 \mathrm{~cm}( \pm 4 \mathrm{~cm})$, and BCS of 3.25 (range: 2.75-4.00). Body size was assessed using a combination of BW, BCS, and height at the withers. Body condition was scored by 2 persons using a 5 -point scale $(1=$ severely underconditioned, $5=$ severely over- conditioned) with quarter-point increments (Edmonson et al., 1989).

The 4 socially stable resident groups each contained 11 animals and were housed in pens that were located adjacent to each other. All resident groups were given at least $10 \mathrm{~d}$ to stabilize before experimental regrouping. The resident groups were balanced for parity, DIM, projected 305-d milk production, and body size. Overall, animals of the resident group had an average $( \pm \mathrm{SD})$ parity of $2.8( \pm 1.7)$, DIM of $291( \pm 55)$, projected 305-d milk production of $11,184 \mathrm{~kg}( \pm 1,542 \mathrm{~kg})$, weight of 728 $\mathrm{kg}( \pm 70 \mathrm{~kg})$, height of $148 \mathrm{~cm}( \pm 5 \mathrm{~cm})$, and BCS of 3.25 (range: $2.75-4.00$ ).

Each pen consisted of 12 lying stalls that contained $40 \mathrm{~cm}$ of washed river sand. Accessible feed bunk space was $60 \mathrm{~cm} /$ animal (with 12 animals/pen). Animals accessed the feed bunk via a post-and-rail feed barrier (for a detailed description, see Huzzey et al., 2006). The animals were fed a TMR consisting of $23.4 \%$ corn silage, $50.4 \%$ concentrate mash, $24.4 \%$ grass silage, and $1.8 \%$ alfalfa hay on a DM basis. Fresh feed was provided twice daily at approximately 0630 and 1630 h. Fresh feed was always first accessed after return from milking. Feed was pushed up at approximately 1100, 1830, and $2230 \mathrm{~h}$, and the orts were removed at approximately $0600 \mathrm{~h}$. The animals had ad libitum access to fresh water, provided in 1 water bin $(1.96 \times 0.54 \mathrm{~m})$, which was located in the crossover alley and shared between 2 pens. Concrete alleys were cleaned 6 times per day with an automated scraper. Cows were milked twice daily, between 0630 and $0730 \mathrm{~h}$ and between 1630 and $1730 \mathrm{~h}$.

Each week (for a total of $8 \mathrm{wk}$ ), animals were individually regrouped into 1 of the 4 resident groups, with 1 primiparous cow regrouped early and the other regrouped late; the same was true for multiparous cows. Early-regrouped animals $(\mathrm{n}=16)$ were individually introduced into a resident group at $0300 \mathrm{~h}$, approximately $10.5 \mathrm{~h}$ after the last delivery of fresh feed and $3.5 \mathrm{~h}$ before the next fresh feed delivery. Late-regrouped animals $(\mathrm{n}=16)$ were introduced into a resident group after morning milking (between 0630 and $0730 \mathrm{~h}$ ), coinciding with access to fresh feed. Both regroupings took place on the same day. Regroupings were undertaken in 2 periods of 4 consecutive weeks with a 2-wk break at the midpoint of the experiment. A few cows of the resident group became lame (i.e., the presence of an obvious limp); the break allowed us to replace these animals with healthy animals and for the resident groups to restabilize. To ensure consistency across groups, 2 animals per group (which included the lame cows) were replaced with healthy, nonlame animals (i.e., in groups where there was no or 1 lame animal, 1 or 2 randomly selected healthy animals were replaced with new healthy animals). 
Regrouped animals remained in the resident group for $3 \mathrm{~d}$, after which they were returned to their home pen. The resident group was then allowed at least 3 d to stabilize before the next animal was introduced. Behaviors were recorded during the complete regrouping period of each animal using 1 dome video camera (Panasonic WV-CW504SP, Sentinel Ultra-Zoom w/ Pan 1070 outdoor video camera, Sandpiper Technologies Inc., Manteca, CA) per pen, positioned approximately $8 \mathrm{~m}$ above the center of each pen, providing an overview of the lying area. A second video camera (Panasonic WVCP-470, Panasonic Corporation of North America, Newark, NJ) was placed $6 \mathrm{~m}$ above the feed bunk of each experimental pen to provide an overview of the feeding area (i.e., feed bunk and feed alley). All video recordings were stored using a GeoVision 1480 digital recorder (USA Vision Systems, Irvine, $\mathrm{CA})$. Red lights $(100 \mathrm{~W})$ were placed above the pens to aid in the observation of the cows during the night. Individual animals were identified using an alphanumeric symbol that was made on their back with hair dye.

Using 5-min scan sampling, feeding (validated by Mitlöhner et al., 2001) and perching behaviors of the regrouped animals were scored from video. The regrouped animal was recorded as feeding when both her ears were past both feed rails of the post-and-rail feed barriers (see Huzzey et al., 2006). Perching was defined as the cow standing with only her 2 front feet in a lying stall. Initiated and received displacements at the feed bunk were scored for the regrouped animal using continuous sampling from video recordings. A displacement from the feed bunk was defined as the actor making physical contact with the reactor, after which the reactor retreated from the feed bunk (i.e., both ears retreated from at least the front rail of the feed barrier). One observer scored all displacements. Interobserver reliability was calculated by comparing the total number of scored displacements of 8 animals during 24 $\mathrm{h}$ by one observer with the same observations made by another independent observer (Pearson $\mathrm{r}=0.94$ ). Data loggers (Hobo Pendant G, Onset, Cape Cod, MA; validated by Ledgerwood et al., 2010) were used to quantify the total time spent lying and the number of standing bouts per day of the regrouped animal (UBC AWP, 2013). The data logger was attached to a hind leg of each regrouped animal $1 \mathrm{~d}$ before regrouping. Loggers were programmed to record the posture of the cow (i.e., lying or standing) at 1-min intervals. Milk production was automatically recorded at each milking.

Two primiparous cows (1 from each treatment) were excluded from all analyses because they showed signs of estrus. Another multiparous cow (early regrouped) and 2 primiparous cows ( 1 from each treatment) were excluded from all analyses because their pens were inadvertently mixed after morning milking at $\mathrm{d} 1$ or 2. Another multiparous cow (late regrouped) was excluded from all analyses because she was diagnosed with clinical mastitis. Two primiparous cows (early regrouped) and 2 multiparous cows (late regrouped) had to be excluded from the video analysis due to technical failures of the recording equipment. One primiparous cow (late regrouped) was deleted from the analysis of lying behavior due to malfunctioning of her Hobo data logger. Statistical analyses were performed with SAS (version 9.4; SAS Institute Inc., Cary, NC) considering the regrouped animal as the observational unit. Model residuals were normally distributed, and no outliers were identified. Analyses were performed using PROC MIXED. For all models, type 1 sum of squares was obtained. With regard to behavioral variables, the model included (in this order) parity (i.e., primiparous vs. multiparous), treatment (i.e., early vs. late regrouping), parity $\times$ treatment, experimental day, experimental day $\times$ parity, and treatment $\times$ experimental day as fixed effects. Cow ID nested within pen was specified as a repeated measure, and autoregressive type 1 was specified as the covariance structure; pen was included as random effect, and Satterthwaite degrees of freedom approximation was used. To investigate differences in feeding time during the first hour after fresh feed delivery on experimental $d 1$, the model included (in this order) parity, treatment, and parity $\times$ treatment, with pen specified as a random effect. The average daily milk production of the $3 \mathrm{~d}$ before regrouping was compared with the average daily production during $\mathrm{d} 2$ and 3 after regrouping (cows were regrouped either before or after morning milking on experimental d 1 , so this day was not included in the analysis). In the following order, the model to test milk production included parity, treatment, parity $\times$ treatment, period (i.e., before vs. after regrouping), period $\times$ parity, and treatment $\times$ period as fixed effects. Cow ID nested within pen was specified as a random effect. For all models, nonsignificant interactions were dropped; significance was declared at $P<0.05$.

No differences in daily feeding times were found between treatments (Table 1) or over the experimental days (Table 2). In addition, no difference in feeding time between treatments $\left(F_{1,19}=0.81, P=0.3797\right.$; early: $14.7 \pm 4.2$; late: $19.8 \pm 4.0 \mathrm{~min})$ was found during the first hour after the first fresh feed delivery on experimental d 1 . We also did not find any differences in daily lying times or the number of standing bouts between treatments or over the experimental days. Daily perching time did not differ between treatments and decreased with experimental day. The number of 
Table 1. Mean ( \pm SEM) time spent feeding and perching in the freestall pen and number of displacements at the feed bunk (as observed from video recordings) as well as lying time and number of standing bouts (as recorded by Hobo data loggers; Hobo Pendant G, Onset, Cape Cod, MA)

\begin{tabular}{|c|c|c|c|c|}
\hline Item & \multicolumn{2}{|c|}{ Treatment $^{1}$} & $F$-value & $P$-value \\
\hline \multicolumn{5}{|l|}{ Video observations } \\
\hline Perching (\% of time observed/d) & $6.4 \pm 1.4$ & $9.5 \pm 1.4$ & $F_{1,19.1}=2.43$ & 0.1356 \\
\hline Displacements (no./d) & $26.7 \pm 3.1$ & $32.2 \pm 3.0$ & $F_{1,19.5}=1.64$ & 0.2151 \\
\hline \multicolumn{5}{|l|}{ Hobo data loggers } \\
\hline
\end{tabular}

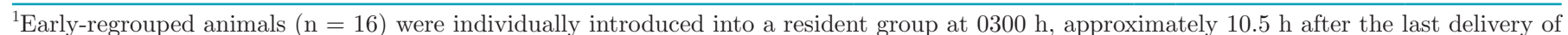
fresh feed and $3.5 \mathrm{~h}$ before the next fresh feed delivery. Late-regrouped animals $(\mathrm{n}=16)$ were introduced into a resident group after morning milking (between 0630 and $0730 \mathrm{~h}$ ), coinciding with access to fresh feed.

displacements at the feed bunk did not differ between treatments and decreased with experimental day. Milk production decreased after regrouping $\left(F_{1,25}=13.08\right.$, $P=0.0013$; before: $32.3 \pm 1.5 \mathrm{~kg} / \mathrm{d}$; after: $30.6 \pm 1.5$ $\mathrm{kg} / \mathrm{d}$ ), with no effect of treatment.

No differences in daily feeding time were found in our study, similar to what has been reported in other regrouping studies (e.g., von Keyserlingk et al., 2008; Schirmann et al., 2011; Talebi et al., 2014). von Keyserlingk et al. (2008) found that during the first day after regrouping, cows had decreased feeding time during the first hour after fresh feed delivery. Although feeding times in this hour may have been decreased compared with before regrouping, early or late regrouping did not affect time spent feeding in the first hour after fresh feed delivery, suggesting that a few hours of experience with new pen mates before fresh feed delivery is not sufficient to mitigate agonistic interactions at the feed bunk.

We also found that the daily number of displacements at the feed bunk did not differ between treatments; this result suggests that a few hours of experience with a new group of cows does not decrease the number of displacements at the feed bunk when cows are later fed. We were unable to include measurements of DMI and rumination in our study, but we encourage future regrouping studies to include these measures.

Increased aggression after regrouping has been observed in other species, including pigs (Algers et al., 1990) and poultry (Cloutier and Newberry, 2002). In the current study, we found that the number of displacements at the feed bunk decreased over time; this result agrees with other regrouping studies reporting the highest number of interactions on the day of regrouping (Brakel and Leis, 1976; von Keyserlingk et al., 2008).

No differences in lying time were found between the treatments or over the experimental days. Cows may have been able to compensate for any initial decrease in lying time by changing their behavior later in the day, explaining the lack of differences in daily averages. Some other work has shown that regrouping decreases lying time (e.g., Hasegawa et al., 1997; von Keyserlingk et al., 2008; Talebi et al., 2014), but other studies found no difference (Schirmann et al., 2011). Given that lying time can vary depending on various internal and external factors and can therefore be highly variable, it is not surprising that inconsistent results for lying

Table 2. Regression lines showing the effect of experimental day on time spent feeding and perching when in the freestall pen and number of displacements at the feed bunk (as observed from video recordings) as well as lying time and number of standing bouts (as recorded by Hobo data loggers; Hobo Pendant G, Onset, Cape Cod, MA)

\begin{tabular}{lcl}
\hline Behavior & Effect of experimental day ${ }^{1}$ & $F$-value \\
\hline Video observations & $15.6( \pm 1.5)+0.4( \pm 0.4)$ & $P$-value \\
Feeding (\% of time observed/d) & $10.3( \pm 1.7)-1.0( \pm 0.4)$ & $F_{1,51.5}=1.00$ \\
Perching (\% of time observed/d) & $40.7( \pm 4.7)-5.0( \pm 1.5)$ & $F_{1,48.4}=7.24$ \\
$\quad$ Displacements (no./d) & $11.4( \pm 0.7)+0.2( \pm 0.2)$ & $F_{1,56.5}=11.10$ \\
Hobo data loggers & $13.9( \pm 1.2)-0.2( \pm 0.2)$ & $F_{1,62.9}=1.58$ \\
Lying (h/d) & $F_{1,56.4}=0.72$ & 0.3231 \\
Standing bouts (no./d) & & 0.0098 \\
\hline
\end{tabular}

\footnotetext{
${ }^{1}$ Intercept and slope $( \pm \mathrm{SEM})$.
} 
time are found. Hence, the reliability of lying time as a behavioral indicator of the disturbance of regrouping can be questioned.

The number of daily standing bouts did not differ between treatments or days. Schirmann et al. (2011) found an increase in the number of lying bouts on the day of regrouping and the day after regrouping, and von Keyserlingk et al. (2008) found a decrease in the number of lying bouts on the day of regrouping. Given these variable results, we suggest that the number of standing bouts also may not be a reliable indicator of the effect of regrouping.

In the current study, we found a decrease in perching time over experimental days. This decline can be perceived as positive; perching may be used to avoid other cows (Cook and Nordlund, 2009), so a decrease in perching may indicate that cows became less fearful of pen mates over this period. To our knowledge, no other regrouping studies investigated perching behavior. Given our results, we encourage future regrouping studies to include perching behavior.

Milk production decreased after regrouping, as reported in other studies (Brakel and Leis, 1976; Hasegawa et al., 1997; von Keyserlingk et al., 2008). The lack of treatment difference in our study is not surprising given the lack of difference in feeding behavior and presumably feed intake.

We expected that regrouping at a quiet time of day would be positive, but regrouping cows at $0300 \mathrm{~h}$ may have disturbed rest for cows in the resident group. Our rationale for regrouping at night, rather than during the day, was that more cows are lying down and fewer cows are present at the feed bunk at night (DeVries et al., 2005). Hence, we expected fewer competitive interactions among cows regrouped at night. We encourage future research to consider regrouping at other quiet times that may also be less likely to disturb the other cows - for example, at around noon.

Our study was conducted with small resident groups; studying regrouping in larger groups might be of interest. Kondo et al. (1989) found no clear association between the number of agonistic interactions and group size in adult cattle, but this study also used group sizes that were relatively small (the second largest herd size observed was 31 to 50 cattle, and only 1 herd with 90 cattle was observed). Jensen and Proudfoot (2017) showed that cows that were regrouped into a smaller group (i.e., 6 cows) were involved in fewer agonistic interactions than were cows regrouped into a larger group (i.e., 24 cows). The effects of early and late regrouping on the resident groups should also be investigated because regrouping is a stressful event not only for the regrouped animal but also for the resident animals (Schirmann et al., 2011).
In addition to social stress associated with the formation of new relationships, separation from established social partners may be stressful. Various studies have shown that cows form social relationships with other cows. Cows that grow up together and that shared their last dry period together have closer relationships (Gygax et al., 2010; Gutmann et al., 2015). Regrouping familiar animals in pairs has been shown to mitigate the negative effects of regrouping (O'Connell et al., 2008; Gygax et al., 2009).

Regrouping at a time not associated with fresh feed delivery did not mitigate the negative effects of regrouping. New work is required to identify ways to reduce the number of regroupings on farms and to mitigate the harmful effects of regrouping when it does occur.

\section{ACKNOWLEDGMENTS}

We thank the staff of the University of British Columbia's Dairy Education and Research Centre (Agassiz, BC, Canada) for their help with the experiment. We also thank Anne Marie De Passilé, Jeffrey Rushen, and Doug Veira of Agriculture and Agri-Food Canada (Agassiz, BC, Canada) for their valuable comments throughout the process. We thank Kees van Reenen of Wageningen Livestock Research, Wageningen University \& Research (Wageningen, the Netherlands) for his suggestions for the analysis and his comments on the results. We thank members of the University of British Columbia's Animal Welfare program, in particular Annett Gefrom and Justine Guillo for their help with the video analysis, João Costa, Heather Neave, and Gosia Zobel for their help with the video equipment, Julia Lomb for her help with the data loggers, and Annabelle Beaver for her critical reflections on our statistical analyses. We are also grateful to Gijs Smid for his help with the video analysis. Anne-Marieke Smid was funded by a travel grant generously provided by the University of British Columbia. This research was funded by a grant provided to Marina von Keyserlingk and Dan Weary, made possible by the Natural Sciences and Engineering Research Council of Canada (NSERC; Ottawa, ON, Canada) through the Industrial Research Chair program with industry contributions provided from the Dairy Farmers of Canada (Ottawa, ON, Canada), British Columbia Dairy Association (Burnaby, BC, Canada), Westgen Endowment Fund (Abbotsford, BC, Canada), Intervet Canada Corporation (Kirkland, QC, Canada), Zoetis (Kirkland, QC, Canada), BC Cattle Industry Development Fund (Kamloops, BC, Canada), Alberta Milk (Edmonton, AB, Canada), Valacta (St. Anne-de-Bellevue, QC, Canada), and CanWest DHI (Guelph, ON, Canada). 


\section{REFERENCES}

Algers, B., P. Jensen, and L. Steinwall. 1990. Behaviour and weight changes at weaning and regrouping of pigs in relation to teat quality. Appl. Anim. Behav. Sci. 26:143-155. https://doi.org/10.1016/ 0168-1591(90)90094-T.

Bøe, K. E., and G. Færevik. 2003. Grouping and social preferences in calves, heifers and cows. Appl. Anim. Behav. Sci. 80:175-190.

Brakel, W. J., and R. A. Leis. 1976. Impact of social disorganization on behavior, milk yield, and body weight of dairy cows. J. Dairy Sci. 59:716-721.

Cloutier, S., and R. C. Newberry. 2002. A note on aggression and cannibalism in laying hens following re-housing and re-grouping. Appl. Anim. Behav. Sci. 76:157-163. https://doi.org/10.1016/ S0168-1591(02)00004-7.

Cook, N. B., and K. V. Nordlund. 2004. Behavioral needs of the transition cow and considerations for special needs facility design. Vet. Clin. North Am. Food Anim. Pract. 20:495-520. https://doi.org/ 10.1016/j.cvfa.2004.06.011.

Cook, N. B., and K. V. Nordlund. 2009. The influence of the environment on dairy cow behavior, claw health and herd lameness dynamics. Vet. J. 179:360-369. https://doi.org/10.1016/j.tvjl.2007 .09 .016 .

DeVries, T. J., and M. A. G. von Keyserlingk. 2005. Time of feed delivery affects the feeding and lying patterns of dairy cows. J. Dairy Sci. 88:625-631.

DeVries, T. J., M. A. G. von Keyserlingk, and K. A. Beauchemin. 2005. Frequency of feed delivery affects the behavior of lactating dairy cows. J. Dairy Sci. 88:3553-3562.

Edmonson, A. J., I. J. Lean, L. D. Weaver, T. Farver, and G. Webster. 1989. A body condition scoring chart for Holstein dairy cows. J. Dairy Sci. 72:68-78. https://doi.org/10.3168/jds.S0022 -0302(89)79081-0.

Galindo, F., D. M. Broom, and P. G. G. Jackson. 2000. A note on possible link between behaviour and the occurrence of lameness in dairy cows. Appl. Anim. Behav. Sci. 67:335-341.

Gutmann, A. K., M. Špinka, and C. Winckler. 2015. Long-term familiarity creates preferred social partners in dairy cows. Appl. Anim. Behav. Sci. 169:1-8. https://doi.org/10.1016/j.applanim.2015.05 .007 .

Gygax, L., G. Neisen, and B. Wechsler. 2009. Differences between single and paired heifers in residency in functional areas, length of travel path, and area used throughout days 1-6 after integration into a free stall dairy herd. Appl. Anim. Behav. Sci. 120:49-55. https://doi.org/10.1016/j.applanim.2009.05.002.

Gygax, L., G. Neisen, and B. Wechsler. 2010. Socio-spatial relationships in dairy cows. Ethology 116:10-23. https://doi.org/10.1111/ j.1439-0310.2009.01708.

Hasegawa, N., A. Nishiwaki, K. Sugawara, and I. Ito. 1997. The effects of social exchange between two groups of lactating primiparous heifers on milk production, dominance order, behavior and adrenocortical response. Appl. Anim. Behav. Sci. 51:15-27.
Huzzey, J. M., T. J. DeVries, P. Valois, and M. A. G. von Keyserlingk. 2006. Stocking density and feed barrier design affect the feeding and social behavior of dairy cattle. J. Dairy Sci. 89:126-133.

Jensen, M. B., and K. L. Proudfoot. 2017. Effect of group size and health status on behavior and feed intake of multiparous dairy cows in early lactation. J. Dairy Sci. 100:9759-9768. https://doi .org/10.3168/jds.2017-13035.

Kondo, S., and J. F. Hurnik. 1990. Stabilization of social hierarchy in dairy cows. Appl. Anim. Behav. Sci. 27:287-297.

Kondo, S., J. Sekine, M. Okubo, and Y. Asahida. 1989. The effect of group size and space allowance on the agonistic and spacing behavior of cattle. Appl. Anim. Behav. Sci. 24:127-135.

Ledgerwood, D. N., C. Winckler, and C. B. Tucker. 2010. Evaluation of data loggers, sampling intervals, and editing techniques for measuring the lying behavior of dairy cattle. J. Dairy Sci 93:5129-5139.

Lobeck-Luchterhand, K. M., P. R. B. Silva, R. C. Chebel, and M. I. Endres. 2014. Effect of prepartum grouping strategy on displacements from the feed bunk and feeding behavior of dairy cows. J. Dairy Sci. 97:2800-2807.

Mitlöhner, F. M., J. L. Morrow-Tesch, S. C. Wilson, J. W. Dailey, and J. J. McGlone. 2001. Behavioral sampling techniques for feedlot cattle. J. Anim. Sci. 79:1189-1193.

O'Connell, N. E., H. C. F. Wicks, A. F. Carson, and M. A. McCoy. 2008. Influence of post-calving regrouping strategy on welfare and performance parameters in dairy heifers. Appl. Anim. Behav. Sci. 114:319-329. https://doi.org/10.1016/j.applanim.2008.03.004.

Raussi, S., A. Boissy, E. Delval, P. Pradel, J. Kaihilahti, and I. Veissier. 2005. Does repeated regrouping alter the social behaviour of heifers? Appl. Anim. Behav. Sci. 93:1-12. https://doi.org/10.1016/ j.applanim.2004.12.001.

Schirmann, K., N. Chapinal, D. M. Weary, W. Heuwieser, and M. A. G. von Keyserlingk. 2011. Short-term effects of regrouping on behavior of prepartum dairy cows. J. Dairy Sci. 94:2312-2319.

Talebi, A., M. A. G. von Keyserlingk, E. Telezhenko, and D. M. Weary. 2014. Reduced stocking density mitigates the negative effects of regrouping in dairy cattle. J. Dairy Sci. 97:1358-1363.

UBC AWP. 2013. University of British Columbia Animal Welfare Program: SOP - HOBO Data Loggers. University of British Columbia, Vancouver, Canada. Accessed Aug. 31, 2017. http://lfs-awp .sites.olt.ubc.ca/files/2013/11/SOP-HOBO-Datalogger-november -2013.pdf.

Val-Laillet, D., A. M. Passillé, J. Rushen, and M. A. G. von Keyserlingk. 2008a. The concept of social dominance and the social distribution of feeding-related displacements between cows. Appl. Anim. Behav. Sci. 111:158-172.

von Keyserlingk, M. A. G., D. Olenick, and D. M. Weary. 2008. Acute behavioral effects of regrouping dairy cows. J. Dairy Sci. 91:10111016 . 